\title{
SYMBOLIC INTERACTIONISM AS A THEORETICAL PERSPECTIVE FOR THE STUDY OF CHILDREN'S ARTISTIC DEVELOPMENT
}

\section{Pat Tarr}

The Piagetian view of children's cognitive development has dominated post World War II child development research in North America. Art education has been influenced by Piaget's constructivist view of child development and by the views expounded by Lowenfeld as early as 1947 (Lowenfeld \& Brittain, 1975), and others such as Kellogg (1970), in which teachers were to leave children's artistic development, or production of visual forms using such media as drawing, painting, or modelling materials, to a natural unfolding process, unimpeded by external influences. The teacher's role was to encourage children's self-expression but not to teach children how to make art. While Smith (1982, p. 298) has criticized Lowenfeld for lacking a "general theory of cognitive-affective development in art", Lowenfeld's unfolding view did not conflict with the Piagetian view that children's mental constructions could not be changed by instruction but would develop through children's experience with materials.

In conjunction with this idea of self-taught child art one of the key words in art education in the 20th century, has been "self-expression" which became widely disseminated through Lowenfeld's book, Creative and Mental Growth. In practice, this mode of teaching encourages art based largely on affective characteristics, and skills which the child has gained from his or her own experience with materials.

Few studies have attempted to account for cultural differences or environmental influences on children's artistic development, which I would suggest is due to the strong Piagetian and experiential biases 
in research on artistic development. Light (1986) has reached a similar conclusion about the monopoly Piaget's theory of cognitive development has had on the field of developmental psychology. He wrote (p. 170) "Earlier theoretical positions which attempted to ground an account of cognitive development in the child's social experiences (Mead, 1934; Vygotsky, 1962) were almost totally eclipsed by Piaget's essentially individualistic account of cognitive development."

The Piagetian or constructivist perspective has become so entrenched in the field of psychology that a reality about the nature of children's art has been constructed which had, in turn, determined how we interpret the developmental process and has directed investigations which validate this perspective. However, Light has suggested (p. 170) that in the area of psychology "the hegemony of the cognitive over the social has been challenged, and is increasingly being challenged in contemporary work."

Although recently the Wilsons have investigated peer influence on children's artistic development and have concluded that elementary school-age children learn to draw forms from each other (Wilson $\varepsilon$ Wilson, 1982; 1984), little work has been done to investigate other external influences on the artisitic development of children. One exception is a study by Sherman (1984) in which she observed that preschool children working with clay and styrofoam pieces imitated each other's actions and adapted these actions for their own purposes. Another exception is Alland's (1983) study of children from six cultures drawing with felt pens. He concluded that cultural influences are apparent in children's drawings as soon as they have passed the scribbling stage. These observations of children learning from peers or social influences are important in that they demonstrate that children's artistic development is susceptible to external influences, but they do not address the question of how this social influence occurs. One way to approach this problem is to examine a 
theoretical perspective which would provide a means for investigating how children's artistic development is influenced by its social context.

Ingleby (1986) has presented arguments for a "socialconstructionist paradigm in developmental psychology". He has identified several approaches to the creation of a social-constructionist paradigm, yet found a commonality between them:

What all these approaches have in common is that they break down the individual/society dichotomy via the following two-stage argument. First, human thought, perception and action must be approached in terms of meanings: secondly, the vehicles of 'meaning' are codes (especially language) whose nature is inherently intersubjective. Therefore, mind is an intrinsically social phenomenon. And if psychology is the science of the mind, then the object of psychology is not individuals but .... what goes on in the space between them: that is the codes, which structure action. ( $p$. 305)

In translating this to research in art, the problem can be restated as the need to investigate how children acquire meaning about the nature of and purposes of art, and the expressive or representational potential of art materials.

The purpose of this paper is to suggest that a theory of children's artistic development must consider an interplay between the child's acquisition of meaning and how this acquisition of meaning mediates the child's visual representation, the materials and tools used to create the representation, and the object the child is attempting to represent. I will root my arguments in the symbolic interactionist position which originated in the pragmatic sociology of James, Thomas, Cooley and Mead, (Meltzer, Pertras $\&$ Reynolds, 1975). Blumer (1969, p. 4) has explained the basic premise of symbolic 
interaction as, "the meaning of a thing for a person grows out of the ways in which other persons act toward the person with regard to the thing." I will explore how this notion can be applied to artistic development through demonstrating how society or "others" representing societal views mediate the child's construction of meaning and the visual forms the child creates. Since in this view meaning is socially constructed, the meaning children create through their interactions with materials must be socially constructed. In addition, meaning about the potential and use of the materials, and the child's sense of self which enters into the child's encounter with the materials is socially constructed.

\section{Symbolic Interactionism and Children's Artistic Development}

The tenants of symbolic interactionism were formulated from the posthumously published teachings of $\mathrm{G}$. H. Mead who was a contemporary and friend of Dewey's at the University of Chicago. In the 1960's Blumer consolidated Mead's views into what became known as symbolic interactionism. Based on Mead's views Blumer has presented the following three premises as crucial to the symbolic interactionist perspective:

Human beings act toward things on the basis of the meanings that the things have for them. (p. 2)

The meaning of a thing for a person grows out of the ways in which other persons act toward the person with regard to the thing. Their actions operate to define the thing for the person. (p. 4)

These meanings are handled in, and modified through, an interpretative process used by the person in dealing with the thing he encounters. (p. 2)

Important to the understanding of symbolic interaction is the definition of "objects." Blumer (p. 10) has defined objects as social objects or people, physical objects or things, and abstract objects or 
ideas.

Blumer found the psychological interpretation of meaning arising out of psychological processes of "perception, cognition, repression, transfer of feelings, and association of ideas" limiting as to the kind of meaning which could be constructed. He has described meaning instead as being constructed "through a process of interpretation" ( $p$. $5)$, by actors engaged in social interactions. Meanings, then, according to Blumer (p. 5), are "creations that are formed in and through the defining activities of people engaged in social interaction." This process of interpretation requires that the actor first note to himself the objects which he is interacting with, he process the meanings the things have for him and interpret them in terms of the situation.

Crucial to this interpretative process is an understanding of the construction of the self through interaction with others. Mead (1934) has explained the origins of self and self-consciousness from an environmental and socio-psychological perspective. He wrote, that although a person could be aware of physical sensations with regard to his body, he could not be self-conscious until he took on the attitudes of other people towards himself. In the development of self, the individual absorbs and generalizes the attitudes others hold toward social activity. This forms the "generalized other" or common view which influences the social behavior of the individual.

In Mead's theory, interaction with another is based on gestures, (verbal or nonverbal) which have a triadic relationship whereby the first individual's gesture invokes a response in the second individual, which is then acted on (verbally or gesturally) by the first individual. Meaning is not established until this third component of the interaction has occurred. Mead explained (p. 181), "Responses are meanings in so far as they lie inside of such a conversation of gesture."

Young children have a sense of others before they can see 
themselves as objects, or objectify themselves. They develop a sense of self, as an object separate from the physical body through their interactions with others. Current infancy research (Trevarthan, 1980) has upheld Mead's view that the infant "comes into the world highly sensitive to this so-called 'mimic gesture,' and he exercises his earliest intelligence in his adaption to his social environment" (Mead, p. 369). Continuing his description of the importance of social interaction to young children, Mead has stated (p. 139) that through play the child is "gradually building up a definite self that becomes the most important object in his world."

Vygotsky, writing at a similar time in Russia, stated this idea in a similar manner, "every function in the child's cultural development appears twice: first on the social level, and later on the individual level; first between people (interpsychological), and then inside the child (intrapsychological)" (Vygotsky, 1978, p. 57).

Having presented some of the ideas basic to the symbolic interactionist perspective, it seems appropriate to explore how these ideas relate to children's artistic development. Two aspects of the theory discussed are important to children's development in the creation of visual forms. The first is the development of the child's sense of self and the second is the meaning objects, including art materials and objects represented, come to have for the child.

As infancy research has demonstrated, the construction of self through interactions with others begins at birth. When the child begins to engage in the use of art materials, the self is well under construction through interactions composed of gestures and language. At about the age of three the child begins to take on the roles others in his environment take toward him. The child brings his or her view of self to the interaction with art materials. The child's self view, and ability to reflect on her or his interactions with materials, arising out of this view of self, is manifested in how the child uses the materials, and how he or she expresses self through the use of 
materials. As we have seen, pedagogical practices have encouraged children to express their sense of self through the use of art materials. In cultures where art is perceived to have other functions than personal self-expression, children are directed more carefully in particular ways of mark-making and ultimate symbolic formations. For example, Soviet preschool children are given direct instruction in art (Morton, 1972) and Alland found that Taiwanese children were encouraged to learn to make $\mathrm{C}$ hinese characters at home rather than encouraged to draw or paint.

This mediation also holds true for the transmitting of the symbolic potential of the materials. In this way, not only the child's sense of self has an important role in how the child uses the materials but also the way materials are expected to be used is mediated for the child by society.

Vygotsky has defined children's acquisition of culture as occurring through their acquisition of the sign systems, particularly language, of the culture. He noted that "the use of signs leads humans to a specific structure of behavior that breaks away from biological development and creates new forms of a culturally-based psychological process" (Vygotsky, p. 40).

Our past dependence on a constructivist view of development has perpetuated a view that art for children rests with them exploring or interacting with materials. Looking at artistic development from an interactionist perspective will allow researchers to investigate the role social interaction plays in children's acquisition of meaning about art, how they come to understand the representational potential of art materials, and how culture shapes artistic expression.

\section{References}

Alland, A., Jr. (1983). Playing with form: Children draw in six cultures. New York: Columbia University.

Blumer, H. (1969). Symbolic interactionism: Perspective and method. 
Englewood Cliffs, NJ: Prentice-Hall.

Ingleby, D. (1986). Development in social context. In M. Richards $\varepsilon$

P. Light (Eds.), Children of social worlds. Cambridge, MA:

Harvard University Press.

Kellogg, R. (1970). Analyzing children's art. Palo Alto, C A:

National Press Books.

Light, P. (1986). Context, conversation and conversation. In M.

Richards \& P. Light (Eds.), Children of social worlds. Cambridge,

MA: Harvard University Press.

Lowenfeld, V. and Brittain, W. L. (1975). Creative and mental growth.

(6th ed.). Toronto: Collier-Macmillan.

Mead, G. H. (1934). Mind, self and society. Chicago: University of

Chicago Press.

Meltzer, B., Petras, J. and Reynolds, L. (1975). Symbolic

interactionism: Genesis, varieties and criticism. Boston:

Routledge $\varepsilon$ Kegan Paul.

Morton, M. (1972). The arts and the Soviet child. Toronto: CollierMacmillan.

Sherman, L. (1984). Three-dimensional media for communication, expression and socialization (pre-school). In R. MacGregor, (Ed.).

Readings in Canadian art education. Vancouver, B.C.: Wedge, University of British Columbia.

Smith, N. (1972). Developmental origins of graphic symbolization in the paintings of children three to five. Unpublished doctoral dissertation, Harvard University. (University Microfilms No. 7909892).

Smith, N. (1982). The visual arts in early childhood education: Development and the creation of meaning. In B. Spodek, (Ed), Handbook of research in early childhood education. New York: Free Press.

Trevarthan, C. (1980). The foundations of intersubjectivity:

Development of interpersonal and cooperative understanding in 
infants. In D. Olson (Ed.), The social foundation of language and thought. New York: Norton.

Vygotsky, L. (1978). Mind in society. Cambridge, MA: Harvard University Press.

Wilson, M. and Wilson, B. (1982). The case of the disappearing two-eyed profile: Or how little children influence the drawings of little children. Review of Research in Visual Arts Education, 15, 19-32.

Wilson, B. and Wilson M. (1984). Children's drawings in Egypt: Cultural style acquisition as graphic development. Visual Arts Research, 10 (1), 13-26. 